\section{Teaching the Rhetorical Situation to Improve Disciplinary Literacy}

\author{
Elizabeth J. Threadgill \\ Eric J. Paulson
}

\section{ABOUT THE AUTHORS}

Elizabeth J. Threadgill holds an MFA in Poetry

and a Ph.D. in Developmental Education, both from Texas State University. She is an Assistant Professor of English at Utica College.

Eric J. Paulson is a Professor in the Graduate Program in Developmental Education and Associate Dean of The Graduate College at Texas State University.

esearch supports instruction of the rhetorical situation - the confluence of a writer, a topic, a medium, and an audience-for teaching reading and writing processes (Bunn; 2015; Downs \& Wardle, 2007; Lockhart \& Soliday, 2016; Sanchez, 2009). Flower and Hayes (1981) conceptualized the thinking process needed to successfully address a topic within a rhetorical situation as considering the task, engaging in knowledge about the topic and the audience, and setting goals and monitoring progress. Elements of the task might include the assignment, purpose, context, discipline, or forum. These elements might dictate audience expectations. And knowledge about the tendencies and processes of readers and writers might further shed light on the rhetorical situation. Making the rhetorical situation more transparent improves the likelihood that a reader's goals or a writer's goals align with the needs of the task and the audience. Putting these approaches to the test, Downs and Wardle (2007) designed a course that focuses on the rhetorical situation, answering questions such as, "How does writing work? How do people use writing? What are problems related to writing and reading and how can they be solved?" (Downs \& Wardle, 2007, p. 558). In directly engaging students with rhetorical reading and writing, they found students had (a) an increased self-awareness about writing, (b) improved reading abilities and confidence, and (c) raised awareness of research writing as conversation (Downs \& Wardle, 2007).

In addition to providing a vehicle for teaching reading and writing processes, we suggest that a focus on the rhetorical situation provides a means for improving disciplinary literacy, the understanding that "reading and writing tasks and processes differ based upon the demands, foci, and epistemology of the discipline" (Holschuh \& Paulson, 2013, p. 13). In this Promising Practices article, we will describe several assignments and activities that engage students with the rhetorical situation toward the aim of improving disciplinary literacy: (a) rhetorical reading/ writing questions, (b) a rhetorical analysis essay, and (c) workshops that teach students to read like a writer.

Rhetorical reading/writing questions (e.g. Hairston, 1986) can provide useful guidelines for informal assignments, such as reading responses. For example, Sanchez (2009) asked students to keep a journal for each text they read in which they respond to questions about the rhetorical situation, focusing on (a) the author's purpose, (b) what needs the article is addressing, (c) who the audience is and what the audience is bringing to the text, (d) how the author is influencing readers, and (e) how the article is functioning. found that students engaging in this process showed improvement in reading scores and writing performance. Importantly, we have noted that these rhetorical reading/writing questions are not beneficial when students do not have an opportunity to discuss their responses. However, when students do discuss their responses, these rhetorical reading/writing questions have demonstrated potential for starting conversations about discipline-specific expectations for reading and writing. For example, in writing a reflection on how an example of journalism functions, students might note that most of the important information in the article is in the beginning. But, it is through discussion that students start to speculate about the attention spans of readers and about the print origins of journalism in which an editor might cut out the end of an article for issues of fit on the page. So, it is through discussion that we can encourage students to arrive at the "why?" and to think about issues related to the demands and epistemology of a discipline.

A useful formal assignment for instruction of the rhetorical situation is the rhetorical analysis essay. In a rhetorical analysis essay, students analyze how well an article or essay is written, using criteria such as forum, structure, use of evidence, target audience, and use of rhetorical appeals (logos, pathos, and ethos). So that students improve their awareness of discipline-specific values and conventions, we recommend asking students to write rhetorical analyses of texts in different disciplines. In doing so, our students have identified different types of evidence 
that are valuable to specific disciplines, for example, first-hand accounts in journalism and primary sources from minority voices in history. As another example, students also note structural and style differences in APA versus MLA texts. Accordingly, Wardle (2007) suggests that providing an opportunity for students to conduct rhetorical analyses of texts in a variety of fields improves transfer of knowledge from writing classes to classes in other disciplines.

Reading-focused workshops provide another method for introducing the rhetorical situation to informal or formal reading and writing activities. Using a workshop to integrate reading and writing instruction is not a new concept. In fact, it is a key discussion in Bartholomae and Petrosky's (1986) seminal text for integrating reading and writing. However, Bunn (2015) reimagined the role of the traditional workshop model (in which students respond as a class verbally and in writing to peer writing) to be more inclusive of conscious reading instruction. Bunn (2015) suggested teaching students the Reading Like a Writer (RLW) method. In the RLW method, students are considering choices writers make to determine strategies that writers use that would work best in students' own writing. To improve disciplinary literacy, we recommend practicing this method with texts in different disciplines. Lockhart and Soliday (2016) found that as students learn to read the way a writer does, they are more able to use texts in different disciplines as models for their own writing in those disciplines.

In this article, we have presented an approach to improving the disciplinary literacy practices of college writers that focuses on teaching the rhetorical situation. When instructors include the structured, deliberate asking of rhetorical reading/writing questions with their students, include rhetorical analysis essays as part of their core writing assignments, and utilize workshops that emphasize students reading like a writer, the rhetorical situation becomes part of the context of the educational experience. And when the rhetorical situation is addressed across varied content areas, students' ability to navigate a varied set of disciplinary literacies can be positively impacted.
References

Bartholomae, D., \& Petrosky, A. R. (1986). Facts, artifacts, and counterfacts: Theory and method for a reading and writing course. Upper Montclair, NJ: Boynton/Cook.

Bunn, M. (2015). Reimagining workshop: Recognizing and expanding the role of reading. Pedagogy: Critical Approaches to Teaching Literature, Language, Composition, and Culture, 16(1), 53-71.

Downs, D., \& Wardle, E. (2007). Teaching about writing, righting misconceptions: (Re)envisioning "First-Year Composition" as "Introduction to Writing Studies." College Composition and Communication, 58(4), 552-584.

Flower, L., \& Hayes, J. R. (1981). A cognitive process theory of writing. College Composition and Communication, 32(4), 365-387.

Hairston, M. (1986). Using nonfiction literature in the composition classroom. In B. T. Peterson (Ed.), Convergences: Transactions in reading and writing (pp. 179-188). Urbana, IL: National Council of Teachers of English.

Holschuh, J. P., \& Paulson, E. J. (2013). Terrain of college developmental reading [Invited white paper]. College Reading \& Learning Association. Retrieved from http://www.crla.net/ publications.htm

Lockhart, T., \& Soliday, M. (2016). The critical place of reading in writing transfer (and beyond): A report of student experiences. Pedagogy: Critical approaches to Teaching Literature, Language, Composition, and Culture, 16(1), 23-37.

Sanchez, B. Y. (2009). The effects of rhetorical reading interventions on the reading and writing performances of students enrolled in college composition classes (Doctoral dissertation). Retrieved from ProQuest, UMI Dissertations Publishing.

Wardle, E. (2007). Understanding 'transfer' from FYC: Preliminary results of a longitudinal study. Writing Program Administration, 31(1/2), 6585. 